\title{
Characteristics of the Induction of the Accumulation of Proline by Abscisic Acid and Isobutyric Acid in Detached Rice Leaves
}

\author{
Irene T. Chou, Chien Teh Chen and Ching Huei Kao
}

\author{
Department of Agronomy, National Taiwan University, Taipei, Taiwan, Republic of China
}

\begin{abstract}
The effects of abscisic acid and isobutyric acid on levels of proline in detached rice leaves were compared. The lowest concentration of abscisic acid that induces accumulation of proline in detached rice leaves was much lower than that of isobutyric acid. The accumulation of porline induced by isobutyric acid was associated with acidification of the cell sap, whereas abscisic acid increased levels of proline without decreasing the $\mathrm{pH}$ of the cell sap. Potassium chloride enhanced the accumulation of proline that was induced by abscisic acid, but it did not stimulate that induced by isobutyric acid. Of particular interest is the finding that detached rice leaves treated with fusicoccin showed an increase in levels of proline and a decrease in the $\mathrm{pH}$ of the cell sap. A synergistic increase in levels of proline was observed when fusicoccin and abscisic acid applied simultaneously. However, fusicoccin had no effect on the induction of the accumulation of proline by isobutyric acid. Benzyladenine inhibited the induction by abscisic acid of the accumulation of proline, but it did not inhibit the induction by isobutyric acid. It is concluded that the mode of action of abscisic acid in inducing the accumulation of proline differs from that of isobutyric acid. Our results also indicate that factors other than acidification of the cell sap are involved in regulation of the accumulation of proline.
\end{abstract}

Key words: Abscisic acid - Isobutyric acid — Proline accumulation - Oryza sativa.

Recent reports have suggested that a decrease in intracellular $\mathrm{pH}$, measured as the $\mathrm{pH}$ of the cell sap, is involved in stress-, ABA- and IBA-induced accumulation of proline in wheat coleoptiles and segments of barley leaves (Pesci and Beffagna 1984, 1985, Goring and Plescher 1986). Venekamp (1989) showed that organic acids are the source of drought-induced synthesis of proline in bean plants in the field. Previously, we reported that proline accumulated in detached rice leaves during dark-induced senescence (Wang et al. 1982). More recently, we reported that secretion of protons from detached rice leaves plays a regulatory role in senescence (Chen et al. 1990). Secretion of protons decreases during senescence of detached rice leaves. The present investigation was conducted to compare the effects of ABA and IBA on the levels of proline in detached rice leaves and to test the hypothesis that ABAand IBA-induced changes in levels of proline might be mediated by changes in intracellular $\mathrm{pH}$, as proposed by Pesci and Beffagna (1985).

Abbreviations: BA, benzyladenine; FC, fusicoccin; IBA, isobutyric acid.

\section{Materials and Methods}

Rice (Oryza sativa cv. Taichung Native 1) seedlings were grown as described previously (Kao 1980). Briefly, seedlings were grown on a stainless-steel net floated on half-strength Johnson's modified nutrient solution (Johnson et al. 1975) in a 500-ml beaker. The nutrient solution (pH 4.5) was replaced every three days. Rice seedlings were grown in a greenhouse with natural daylight at $30^{\circ} \mathrm{C}$ by day and $25^{\circ} \mathrm{C}$ by night, with $95 \%$ humidity.

Apical 3-cm segments, excised from the third leaves of 12-day-old seedlings, were used. A group of 20 segments were floated in a Petri dish that contained $20 \mathrm{ml}$ of basal medium ( $1 \mathrm{~mm}$ potassium phosphate, $\mathrm{pH}$ 5.5) or test solutions. All test solutions were prepared by addition of chemicals of interest to $1 \mathrm{~mm}$ potassium phosphate buffer (pH 5.5). Incubations were carried out at $27^{\circ} \mathrm{C}$ in darkness.

Proline was extracted and its concentration determined by the method of Bates et al. (1973). Leaf segments were homogenized with $3 \%$ sulfosalicylic acid and the homogenate was centrifuged. The supernatant was treated 
with acetic acid and acid ninhydrin, boiled for $1 \mathrm{~h}$, and then absorbance at $520 \mathrm{~nm}$ was determined. Levels of proline are expressed as $\mu \mathrm{mol} / \mathrm{g}$ fresh weight.

The method of Pesci and Beffagna (1985) was used to measure the $\mathrm{pH}$ of the cell sap. Leaf segments were transferred at the end of treatment directly into a syringe and were frozen in liquid nitrogen. After thawing, the cell sap was pressed out from the syringe and its $\mathrm{pH}$ was measured.

\section{Results}

Figure 1 shows the changes in levels of proline in detached rice leaves incubated in various concentrations of $A B A$ or IBA in darkness for $8 \mathrm{~h}$. Levels of poline increased with the increase in the concentrations of ABA or IBA. The level of proline was first found to increase in $10 \mu \mathrm{M}$ ABA, but only in $1 \mathrm{~mm}$ IBA. The lowest concentration of $A B A$ to cause increased accumulation of proline was 100 times lower than that of IBA. Figure 1 shows the changes in the $\mathrm{pH}$ of the cell sap of detached leaves incubated in various concentrations of ABA and IBA in the dark for $8 \mathrm{~h}$. The $\mathrm{pH}$ of the cell sap decreased with increases in the concentration of IBA. The pH of the cell sap also decreased during incubation in 1 mM IBA. How-

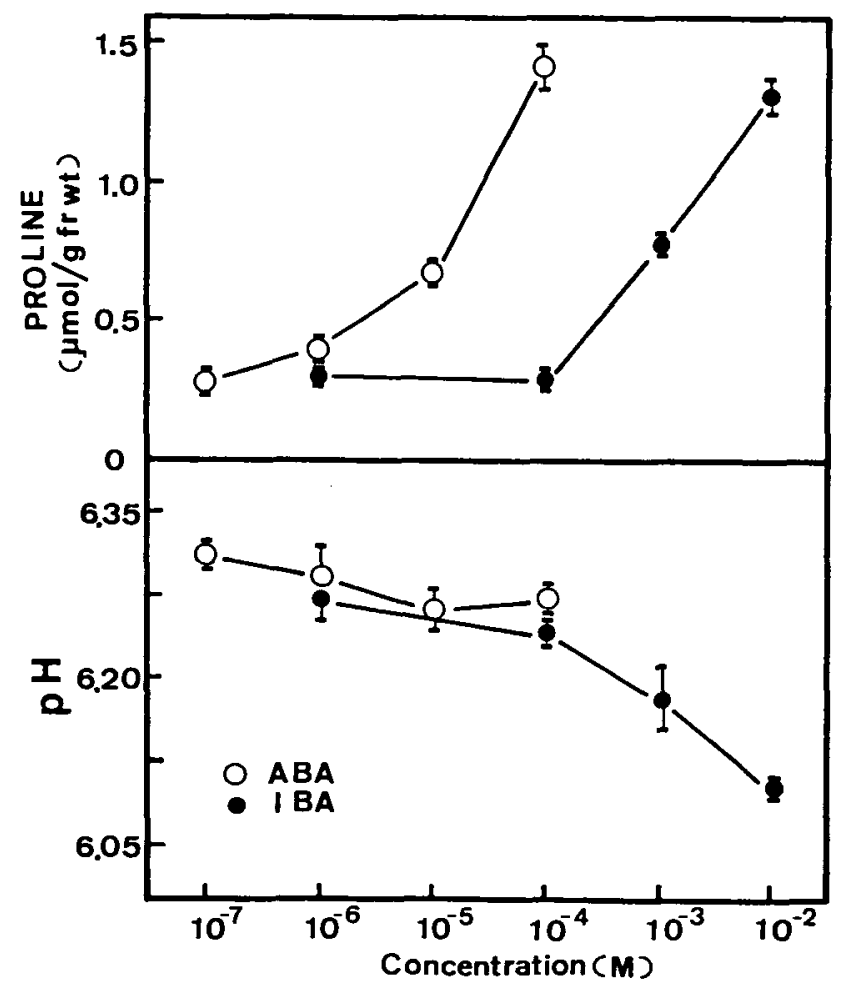

Fig. 1 Effects of various concentrations of ABA and IBA on levels of proline and $\mathrm{pH}$ of the cell sap. Detached rice leaves were incubated in darkness for $8 \mathrm{~h}$. Bars represent SE; 3 replicates.
Table 1 Effects of $\mathrm{KCl}$ on ABA- and IBA-induced accumulation of proline

\begin{tabular}{lc}
\hline Treatment & $\begin{array}{c}\text { Proline level } \\
(\mu \text { mol/g fr wt })\end{array}$ \\
\hline None & $0.25 \pm 0.01$ \\
$\mathrm{ABA}, 10 \mu \mathrm{M}$ & $0.48 \pm 0.04$ \\
$\mathrm{ABA}, 10 \mu \mathrm{M}+\mathrm{KCl}, 50 \mathrm{mM}$ & $0.60 \pm 0.04$ \\
$\mathrm{IBA}, 10 \mathrm{mM}$ & $1.01 \pm 0.09$ \\
$\mathrm{IBA}, 10 \mathrm{mM}+\mathrm{KCl}, 50 \mathrm{mM}$ & $1.06 \pm 0.04$ \\
\hline
\end{tabular}

Detached rice leaves were incubated in the dark for $8 \mathrm{~h}$ in either $\mathrm{ABA}$ or IBA with or without $\mathrm{KCl}$ (mean $\pm \mathrm{SE} ; 4$ replicates).

ever, the $\mathrm{pH}$ was not significantly affected by addition of ABA at the concentration from $0.1 \mu \mathrm{M}$ to $100 \mu \mathrm{M}$. Clearly, the accumulation of proline induced by $\mathrm{BBA}$, and not that induced by $A B A$, was associated with acidification of the cell sap. Since leaf segments treated with $100 \mu \mathrm{M}$ ABA showed slight signs of wilting, $10 \mu \mathrm{M}$ ABA was adopted for subsequent experiments.

The increase in levels of proline induced by ABA in detached barley leaves was stimulated by potassium chloride (Pesci 1987, 1988, Pesci and Beffagna 1986). The effects of potassium chloride on ABA- and IBA-induced accumulation of proline in detached rice leaves were, therefore, compared. Table 1 shows that potassium chloride at $50 \mathrm{~mm}$ stimulated the ABA-induced accumulation of proline, but it did not stimulate the IBA-induced accumulation of proline. These results are in agreement with those observed in

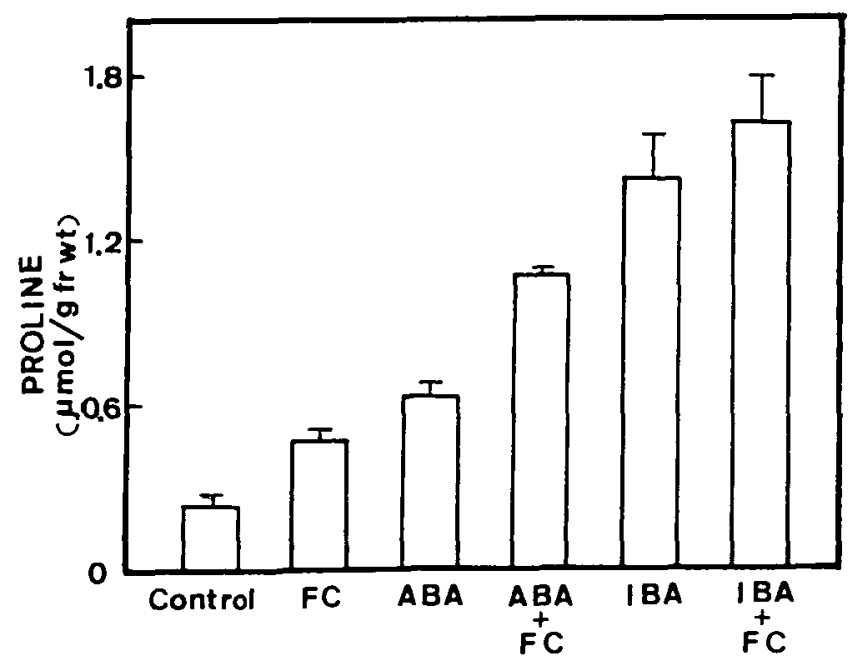

Fig. 2 Effects of fusicoccin (FC) on levels of proline and of FC on ABA- and IBA-induced accumulation of proline. Detached rice leaves were incubated in the dark for $8 \mathrm{~h}$ in $\mathrm{ABA}(10 \mu \mathrm{M})$, IBA $(10 \mathrm{mM}), \mathrm{FC}(10 \mu \mathrm{M}), \mathrm{FC}(10 \mu \mathrm{M})+\mathrm{ABA}(10 \mu \mathrm{M}), \mathrm{FC}(10 \mu \mathrm{M})$ + IBA (10 mM). Bars represent SE; 3 replicates. 
Table 2 Effects of ABA or IBA with or without fusicoccin (FC) and of FC alone on the $\mathrm{pH}$ of the cell sap

\begin{tabular}{lc}
\hline Treatment & $\mathrm{pH}$ of the cell sap \\
\hline Control & $6.20 \pm 0.01$ \\
FC & $6.07 \pm 0.01$ \\
ABA & $6.20 \pm 0.02$ \\
FC + ABA & $6.08 \pm 0.02$ \\
IBA & $6.02 \pm 0.01$ \\
FC + IBA & $6.05 \pm 0.02$ \\
\hline
\end{tabular}

Detached rice leaves were incubated in the dark for $8 \mathrm{~h}$ in ABA $(10 \mu \mathrm{M})$, IBA $(10 \mathrm{mM}), \mathrm{FC}(10 \mu \mathrm{M}), \mathrm{FC}(10 \mu \mathrm{M})+\mathrm{ABA}(10 \mathrm{mM})$, or $\mathrm{FC}(10 \mu \mathrm{M})+\mathrm{IBA}(10 \mathrm{mM})$ (mean $\pm \mathrm{SE} ; 3$ replicates).

the barley leaf system (Pesci 1987, 1988, Pesci and Beffagna 1986). However, the enhancement by potassium chloride on the ABA-induced accumulation of proline in detached rice leaves was much lower than that in the barley system.

The phytotoxin fusicoccin (FC) has been shown to stimulate active export of protons (Marre 1979). To our surprise, FC at $10 \mu \mathrm{M}$ caused not only an increase in levels of proline level but also a decrease in the $\mathrm{pH}$ of the cell sap in our system (Fig. 2 and Table 2). Similar results were observed when the concentration of FC was only $1 \mu \mathrm{M}$ (data not shown). Figure 2 and Table 2 show the effects of IBA and $\mathrm{ABA}$ in the absence and presence of $\mathrm{FC}$ on levels of proline and on the $\mathrm{pH}$ of the cell sap, respectively. IBA-induced accumulation of proline was clearly associated with a decrease in the intracellular pH. However, such was not

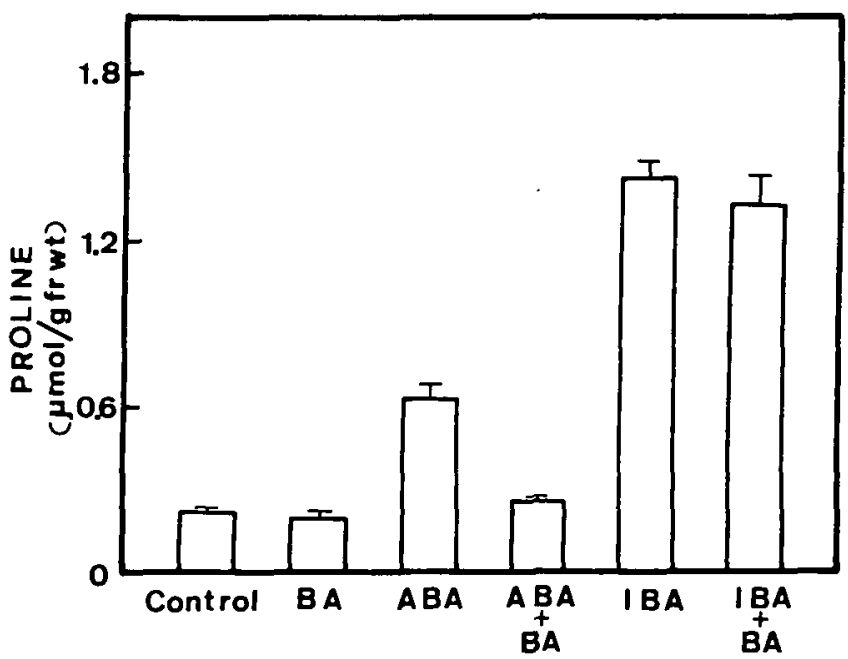

Fig. 3 Effects of benzyladenine (BA) on levels of proline and of $B A$ on ABA- and IBA-induced accumulation of proline. Detached rice leaves were incubated in the dark for $8 \mathrm{~h}$ in $A B A$ $(10 \mu \mathrm{M})$, IBA $(10 \mathrm{mM})$, BA $(10 \mu \mathrm{M})$, BA $(10 \mu \mathrm{M})+\mathrm{ABA}(10 \mu \mathrm{M})$, or BA $(10 \mu \mathrm{M})+$ IBA $(10 \mathrm{mM})$. Bars represent SE; 3 replicates.
Table 3 Effects of ABA or IBA with or without benzyladenine (BA) and of $\mathrm{BA}$ alone on the $\mathrm{pH}$ of the cell sap

\begin{tabular}{lc}
\hline Treatment & $\mathrm{pH}$ of the cell sap \\
\hline Control & $6.32 \pm 0.02$ \\
BA & $6.31 \pm 0.02$ \\
ABA & $6.36 \pm 0.04$ \\
BA + ABA & $6.28 \pm 0.02$ \\
IBA & $6.14 \pm 0.03$ \\
BA + IBA & $6.17 \pm 0.04$
\end{tabular}

Detached rice leaves were incubated in the dark for $8 \mathrm{~h}$ in $\mathrm{ABA}$ $(10 \mu \mathrm{M})$, IBA $(10 \mathrm{mM}), \mathrm{BA}(10 \mu \mathrm{M}), \mathrm{BA}(10 \mu \mathrm{M})+\mathrm{ABA}(10 \mu \mathrm{M})$, or $\mathrm{BA}(10 \mu \mathrm{M})+\mathrm{IBA}(10 \mathrm{mM})($ mean $\pm \mathrm{SE} ; 3$ replicates $)$.

the case in ABA-treated segments of rice leaves. FC stimulated the ABA-induced accumulation of proline. However, FC had no effect on the IBA-induced accumulation of proline. A synergistic effect on the increase in levels of proline was observed when FC and ABA were applied together. No difference was observed between the $\mathrm{pH}$ of cell sap of detached rice leaves treated with $\mathrm{FC}$ alone and the $\mathrm{pH}$ of detached leaves treated with FC and ABA together.

Kinetin has been shown to reduce the extent of the accumulation of proline induced by ABA (Eder and Huber 1977). More recently, it was reported that benzyladenine (BA) inhibited the accumulation of proline in ABA-treated segments of barley leaves (Stewart et al. 1986). We found that BA did inhibit the ABA-induced accumulation of proline in detached rice leaves, but it did not inhibit the IBA-induced accumulation of proline (Fig. 3). No difference was observed between the $\mathrm{pH}$ of the cell sap of detached rice leaves treated with $\mathrm{BA}$ alone and the $\mathrm{pH}$ of those treated with BA and ABA together (Table 3).

\section{Discussion}

The mechanism of the ABA-induced accumulation of proline in detached rice leaves differs from that of the IBAinduced accumulation of proline. This conclusion is based on the observations that (a) the lowest concentration of ABA that induces the accumulation of proline was 100 times lower than that of IBA; (b) potassium chloride stimulated the accumulation of proline that was induced by ABA, but it did not stimulate the IBA-induced accumulation of proline; (c) a synergistic increase in levels of proline was found when FC and ABA were applied together, but FC had not effect on the IBA-induced accumulation of proline; (d) BA did inhibit the accumulation of proline by ABA, but it did not inhibit that induced by IBA; (e) the accumulation of proline induced by IBA was associated with acidification of the cell sap, whereas ABA increased levels of proline without any decrease in the $\mathrm{pH}$ of the cell sap. 
It is apparent that the effect of ABA is a "hormonal" effect (ABA is effective at very low concentrations; it acts synergistically with FC and BA; the increase in levels of of proline is relatively independent of the $\mathrm{pH}$ of the cell sap), whereas the effect of IBA can be explained by the decrease of the $\mathrm{pH}$ of the cell sap.

Of particulr interest is the finding that FC increased levels of proline in detached rice leaves. Although FC is known to promote secretion of protons from detached rice leaves (Chen and Kao 1988), FC was observed to decrease the $\mathrm{pH}$ of the cell sap. The decrease in the $\mathrm{pH}$ of the cell sap after application of FC has been reported by other investigators (Bertel and Felle 1985, Brummer et al. 1985, Hager and Moser 1985, Roberts et al. 1981). FC is a diacetate ester and, according to Hager and Moser (1985), it can be hydrolyzed like naphthylacetate and other carboxyester compounds. Such hydrolysis might explain why FC decreases the $\mathrm{pH}$ of the cell sap. Apparently, the accumulation of proline induced by FC is associated with a decrease in the $\mathrm{pH}$ of the cell sap.

Pesci and Beffagna (1985) reported that FC completely suppressed the ABA-induced increase in levels of proline during a 7 -h treatment period. In contrast to their results, our data indicate that FC promotes the ABA-induced accumulation of proline in detached rice leaves. ABA- and IBA-induced accumulation of proline has been proposed to be mediated by acidification of the cell sap (Pesci and Beffagna 1985). However, our results demonstrate that the accumulation of proline that is induced by IBA, but not by ABA, is associated with acidification of the cell sap. It appears that, in detached rice leaves, factors apart from acidification of the cell sap may also be involved in regulating the accumulation of proline.

At present, it remains unclear whether acidification of the cell sap regulates the accumulation of proline through stimulation of the synthesis of proline, reduction in the utilization of proline, or both. Further studies should provide valuable information on the mechanism of accumulation of proline.

This research was supported by the National Science Council of the Republic of China (NSC 77-0409-B002-11).

\section{References}

Bates, L. S. (1973) Rapid determination of free proline for water stress studies. Plant Soil 39: 205-207.

Bertel, A. and Felle, H. (1985) Cytoplasmic pH of root hair cells of Sinapis alba recorded by a pH-sensitive microelectrode. Does fusicoccin stimulate the proton pump by cytoplasmic acidification? J. Exp. Bot. 36: 1142-1149.

Brummer, B., Bertl, A., Potrykus, I., Felle, H. and Parish, R. W.
(1985) Evidence that fusicoccin and indole-3-acetic acid induce cytosolic acidification of Zea mays cells. Fed. Eur. Biochem. Soc. 189: 109-114.

Chen, C. T. and Kao, C. H. (1988) Proton secretion in rice leaves. Bot. Bull. Academia Sinica 29: 315-320.

Chen, C. T., Chou, I. T. and Kao, C. H. (1990) Senescence of rice leaves $\mathrm{XX}$. Changes of proton secretion during senescence. Plant Sci. 66: 29-34.

Eder, A. and Huber, W. (1977) About the effects of abscisic acid and kinetin on biochemical changes in Pennisetum typhoides during stress conditions. Z. Pflanzenphysiol. 84: 301-311.

Goring, H. and Plescher, F. (1986) Proline accumulation induced by weak acids and LAA in coleoptiles of wheat seedlings. Biol. Plant. 28: 401-406.

Hager, A. and Moser, I. (1985) Acetic acid esters and permeable weak acids induce active proton extrusion and extension growth of coleoptile segments by lowering the cytoplasmic $\mathrm{pH}$. Planta 163: 391-400.

Johnson, C. M., Stout, P. R., Broyer, T. C. and Carlton, A. B. (1957) Comparative chlorine requirements of different plant species. Plant Soil 8: 337-353.

$\mathrm{KaO}$, C. H. (1980) Sensecence of rice leaves IV. Influence of benzyladenine on chlorophyll degradation. Plant Cell Physiol. 21: 339-344.

Marrè, E. (1979) Fusicoccin: a tool in plant physiology. Annu. Rev. Plant Physiol. 30: 273-288.

Pesci, P. (1987) ABA-induced proline accumulation in barley leaf segments: dependence on protein synthesis. Physiol. Plant. 71: 287-291.

Pesci, P. (1988) Ion fluxes and abscisic acid-induced proline accumulation in barley leaf segments. Plant Physiol. 86: 927930.

Pesci, P. and Beffagna, N. (1984) Inhibiting effect of fusicoccin on abscisic acid-induced proline accumulation in barley leaves. Plant Sci. Lett. 36: 7-12.

Pesci, P. and Beffagna, N. (1985) Effect of weak acids on proline accumulation in barley leaves: a comparison between abscisic acid and isobutyric acid. Plant Cell Environ. 8: 129-133.

Pesci, P. and Beffagna, N. (1986) Influence of exogenously supplied potassium and sodium salts on the abscisic acid-induced proline accumulation in barley leaf segments. Physiol. Plant. 67: 123-128.

Roberts, J. K. M., Ray, P. M., Wade-Jardetzky, N. and Jardetzky, O. (1981) Extent of intracellular pH changes during $\mathrm{H}$ extrusion by maize root-tip cells. Planta 152: 76-78.

Stewart, C. R., Voetberg, G. and Rayapati, P. J. (1986) The effect of benzyladenine, cycloheximide, and cordycepin on wilting-induced abscisic acid and proline accumulations and abscisic acid- and salt-induced proline accumulation in barley leaves. Plant Physiol. 82: 703-707.

Venekamp, J. H. (1989) Regulation of cytosol acidity in plants under conditions of drought. Physiol. Plant. 76: 112-117.

Wang, C. Y., Cheng, S. H. and Kao, C. H. (1982) Senescence of leaves VII. Proline accumulation in senescing excised leaves. Plant Physiol. 69: 1348-1349.

(Received September 25, 1990; Accepted December 20, 1990) 